\title{
Optimization of the kinematic mode of operation of the tractor- driven tillage tool
}

\author{
Yuri Saveliev*, Yuri Kirov, Pavel Ishkin and Mikhail Petrov \\ Samara State Agrarian University, Ust-Kinelsky village, Kinel, 446442, Samara region, Russia
}

\begin{abstract}
A traction-driven tillage tool with low traction resistance has been developed. A decrease in the tractive resistance of the implement is achieved by transferring the main share of the power consumed by the implement to the process of loosening the soil through the tractor power take-off shaft (PTO) to the drive needle discs, which in turn create a pushing force. The efficiency of the technological process of soil cultivation depends on the kinematic mode of operation of each row of disk working bodies of the tractiondrive tillage implements. To optimize their kinematic mode of operation, a multifactorial experiment was carried out, which made it possible to establish the optimal values of such factors as the kinematic parameters of the 1 st and 2 nd rows of needle disks at the set operating speed of the unit.
\end{abstract}

\section{Introduction}

In crop production, tillage is one of the most energyintensive operations, it accounts for up to $40 \%$ of the energy costs of the entire technology $[1,2]$. Increasing the energy efficiency of tillage is one of the important tasks in increasing the profitability and environmental friendliness of agricultural production. In this regard, relevant and significant research is aimed at optimizing the technological parameters of machine-tractor units, allowing to increase the efficiency of the use of energy resources in crop production.

Improving the energy efficiency of tillage is possible by means of the use of traction-driven tillage tools with active working bodies that do not create high traction resistances and do not require a large traction-coupling weight of the aggregating tractor [2-5]. The possibility of increasing the energy efficiency of the unit by reducing the tractor wheel slip and rolling losses of the unit, which is achieved by transferring part of the power through the PTO to the drive needle working bodies, which compensate for the traction resistance of the tool and create a pushing force, reducing the rolling resistance.

The use of the proposed traction-drive tool will allow for loosening the soil by stretching with separation and reduce the traction resistance of the tool by transferring the main share of the power consumed by the tool through the shaft of the tractor power take-off mechanism to the drive rotary working bodies, which in turn create a pushing force.

\section{Research objects}

To increase the energy efficiency of soil cultivation, a traction-driven tillage tool has been developed (Fig. 1), which creates a low traction resistance. A decrease in the tractive resistance of the implement is achieved by transferring the main share of the power consumed by the implement to the technological process of loosening the soil through the tractor power take-off shaft to the driven rotary working bodies, which in turn create a pushing force, minimizing the traction resistance of the tillage implement [6].

The traction-driven tillage tool works as follows. Before the start of the movement of the unit, in the transport position of the tool, the shaft of the tractor power take-off mechanism is turned on, from which the torque is transmitted to the front and rear shafts with rotary working bodies-needle disks. Further, the tool is transferred to the working position and the needle disks of the first row with loosening-bearing elements are buried in the soil, performing strip tillage with frontal loosening by separation, and the needle disks of the second row with loosening elements in the form of an isosceles triangle loosen the soil by stretching deformation in adjacent untreated strips by the impact from the line of their symmetry in opposite directions to the loosened strips. At the same time, the circumferential speed of the drive rotary working bodies exceeds by $5 \ldots 15 \%$ the theoretical speed of the tractor in the selected gear, which creates reactions directed towards the movement of the unit.

The tool (Figure 1) contains driven rotary working bodies - needle discs, which are located in two rows. The rows of working bodies are located perpendicular to the direction of movement of the tool in a checkerboard pattern, and are made in the form of batteries of needle disks with needles of optimal curvature [7].

The efficiency of the technological process of the traction-drive tillage implement depends on the kinematic mode of operation of each row of its disc

\footnotetext{
Corresponding author: juri.savelev@ mail.ru
} 
working bodies. To optimize their kinematic mode of operation, a multifactorial experiment was carried out.

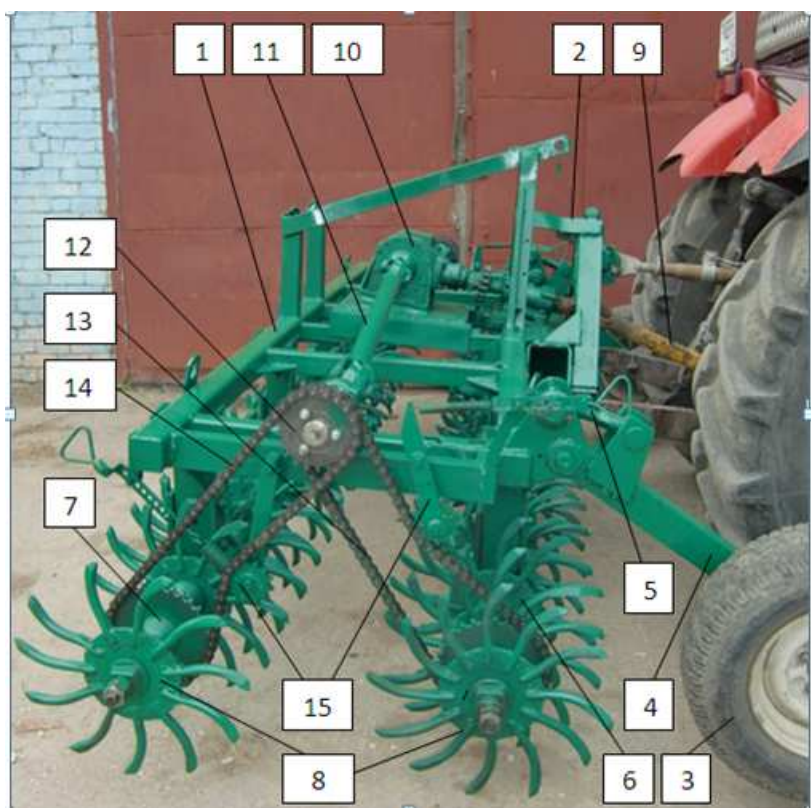

Fig. 1. Experimental traction-drive tillage tool: 1 - frame; 2 hinged device; 3 - support and adjusting wheel; 4 - wheel lever; 5 - screw adjuster of working depth; 6 - front battery of drive disc-needle working bodies; 7 - rear battery of drive discneedle working bodies; 8 - disk-needle working bodies; 9 cardan shaft for transmission of torque from the tractor PTO; 10 - bevel gearbox; 11 - propeller shaft for transferring torque from the bevel gear to the battery of drive disk-needle working bodies; 12 - torque flow distributor with a block of replaceable sprockets; 13 - chain drive circuit for transmitting torque to the front battery of disk-needle working bodies; 14 - chain drive circuit for transmitting torque to the rear battery of disc-needle working bodies; 15 - tensioning mechanisms of chain drives of circuits for transmitting torque to batteries of disk-needle working bodies.

\section{Experimental research methods}

The method of optimization of the kinematic operating mode of the traction-drive tillage unit includes a series of experiments according to the theory of multifactorial planning of experiments [8].

The quality of soil crumbling and the hourly fuel consumption for the implementation of the technological process of soil cultivation were selected as the estimated indicators of the operation of a machine-tractor unit with a traction-drive implement. The optimization criterion was the specific energy consumption Ec $[\mathrm{g} /(\mathrm{h} \cdot \%)]-\mathrm{a}$ relative characteristic of the technological process of soil cultivation, showing the hourly fuel consumption for each percentage of crumbling quality.

Based on the results of preliminary studies, the factors that have the most significant impact on the estimated indicators were identified:

- kinematic parameter of the 1 st row of needle disks $(\mathrm{K} 1)$;

- kinematic parameter of the 2 nd row of needle disks (K2);

- unit operating speed (Vp), $\mathrm{km} / \mathrm{h}$.
The kinematic parameters of the operation of the rotary working bodies of the front and rear rows were set by changing the gear number of the speed row of the tractor and changing the gear ratio of the chain drive of the battery drive. For this, a set of replaceable drive sprockets with the required number of teeth was manufactured (Fig. 2). Thus, a variational series of gear ratios for the front and rear batteries was provided (Table 1).

Table 1. Parameters of chain drives of the drive of the front and rear batteries of rotary working bodies

\begin{tabular}{|c|c|c|c|c|}
\hline \multirow{2}{*}{$\begin{array}{c}\text { Front } \\
\text { batteries }\end{array}$} & $\begin{array}{c}\text { Number of teeth of } \\
\text { the drive sprocket }\end{array}$ & $\mathbf{1 8}$ & $\mathbf{1 9}$ & $\mathbf{2 0}$ \\
\cline { 2 - 5 } & Gear ratio & 1.72 & 1.63 & 1.55 \\
\hline \multirow{2}{*}{$\begin{array}{c}\text { Rear } \\
\text { batteries }\end{array}$} & $\begin{array}{c}\text { Number of teeth of } \\
\text { the drive sprocket }\end{array}$ & $\mathbf{2 0}$ & $\mathbf{2 1}$ & $\mathbf{2 2}$ \\
\cline { 2 - 5 } & Gear ratio & 1.55 & 1.47 & 1.41 \\
\hline
\end{tabular}

The specified set of interchangeable drive sprockets made it possible to vary the ratio of the peripheral speeds of rotation of the front and rear rows of rotary working bodies from 1.0 to 1.22 in accordance with Table 2 .

Table 2. Ratios of the peripheral speeds of rotation of the front and rear rows of rotary working bodies

\begin{tabular}{|c|c|c|c|c|}
\hline \multirow{2}{*}{$\begin{array}{c}\text { Number of teeth of the } \\
\text { drive sprocket }\end{array}$} & \multicolumn{3}{|c|}{ Front batteries } \\
\cline { 2 - 5 } & $\mathbf{1 8}$ & $\mathbf{1 9}$ & $\mathbf{2 0}$ \\
\hline \multirow{2}{*}{$\begin{array}{c}\text { Rear } \\
\text { batteries }\end{array}$} & $\mathbf{2 1}$ & 1.11 & 1.05 & 1.00 \\
\cline { 2 - 5 } & $\mathbf{2 2}$ & 1.17 & 1.11 & 1.05 \\
\hline
\end{tabular}

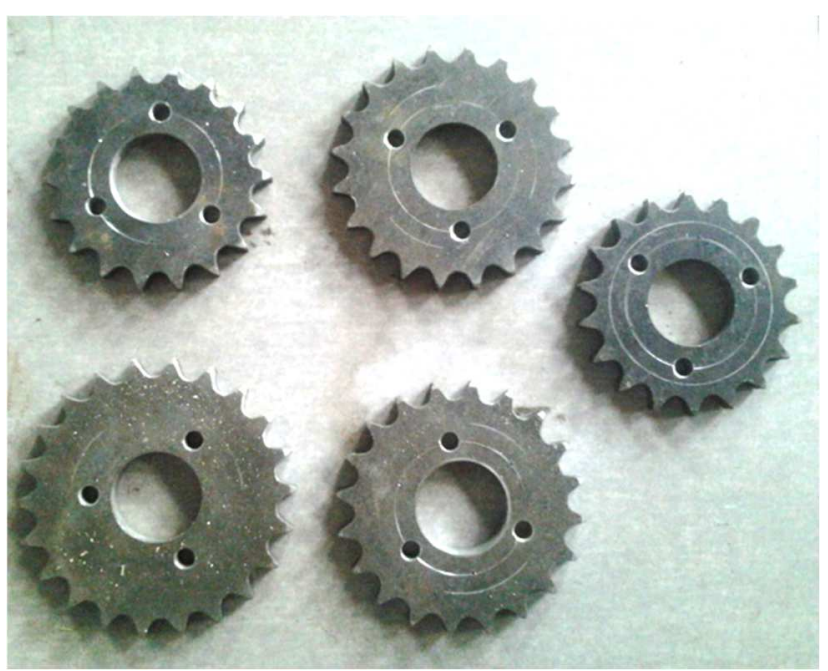

Fig. 2. Set of replaceable drive sprockets with the necessary number of teeth

The control of the set speed of rotation of the combined wild-needle working bodies was carried out on a stationary basis with a Testo 470 tachometer.

Determination of the quality of soil crumbling was carried out according to STO AIST 4.2-2010 Tests of agricultural machinery. Machines and implements for shallow and shallow tillage. Methods for assessing functional indicators of the standard methodology. This technique provided for the selection of soil samples in the treated areas for the entire depth of loosening from 
an area of $0.25 \times 0.25 \mathrm{~m}$. The assessment of the crumbling quality was determined based on the percentage by weight of soil aggregates ranging in size from 0.001 to $0.05 \mathrm{~m}$

Hourly fuel consumption was determined in accordance with the energy assessment methodology in accordance with GOST R 52777-2007 "Tests of agricultural machinery. Methods of Energy Assessment "with the use of the information-measuring system IP264 of the Federal State Budgetary Institution" Povolzhskaya State Zonal Machine Testing Station ".

A series of experiments were carried out according to Pesochinsky symmetric noncompositional quasi-Doptimal plan.

For the analytical description of the influence of factors on the optimization criterion, a quadratic model of the regression equation was chosen:

$$
y=b_{0}+\sum_{1 \leq i \leq k} b_{i} x_{i}+\sum_{1 \leq i \leq j \leq k} b_{i j} x_{i} x_{j}+\sum_{1 \leq i \leq k} b_{i i} x_{i}^{2}
$$

where $y$ is the optimization parameter;

$b_{0}$ is the free term equal to the response at $x_{i}=0$;

$b_{i}$ is an estimation of the coefficient of the regression equation corresponding $i$-th factor;

$b_{i j}$ is an estimation of the coefficient of the regression equation corresponding to the interaction of factors;

$x_{i}$ is a coded value of factors $(i=1,2,3 \ldots)$.

Since the factors of the process are heterogeneous and have different units of measurement, they brought them to a unified system of calculation by moving from the actual values of the factors to those coded according to the formula:

$$
X_{i}=\frac{X_{i}-X_{i 0}}{\Delta X_{i}},
$$

where $X_{i}$ is the natural value of the factor;

$X_{i 0}$ is the natural value of the factor at the main level;

$\Delta X_{i}$ is the natural value of the factor variation interval.

Introduced a conventional designation of the upper, lower and main levels of factors, respectively, $+1 ;-1 ; 0$ (table 3).

Table 3. Levels and intervals of variation of the main factors in regression analysis

\begin{tabular}{|c|c|c|c|c|c|c|}
\hline $\begin{array}{c}\text { Factor } \\
\text { variation } \\
\text { levels }\end{array}$ & \multicolumn{3}{|c|}{ Factors } & \multicolumn{3}{|c|}{$\begin{array}{c}\text { Factors in coded } \\
\text { form }\end{array}$} \\
\cline { 2 - 8 } & $\mathbf{K 1}$ & $\mathbf{K 2}$ & $\mathbf{V p}, \mathbf{~ k m} / \mathbf{h}$ & $\boldsymbol{X}_{\mathbf{1}}$ & $\boldsymbol{X}_{\mathbf{2}}$ & $\boldsymbol{X}_{\mathbf{3}}$ \\
\hline Upper & 1.15 & 1,2 & 11 & +1 & +1 & +1 \\
\hline Lower & 1.05 & 1.1 & 7.2 & -1 & -1 & -1 \\
\hline Main & 1.1 & 1.15 & 9.1 & 0 & 0 & 0 \\
\hline $\begin{array}{c}\text { Variation } \\
\text { interval }\end{array}$ & 0.05 & 0.05 & 1.9 & 1 & 1 & 1 \\
\hline
\end{tabular}

The planning matrix was adopted according to table 4 [3].

To construct a mathematical model in natural variables, coding formulas were used (2). After substituting the natural values of the factors into equation (1), the regression equation was obtained in a decoded form. Using the regression equation in a decoded form, the response surfaces were built and, by the nature of the surfaces, the effect of the unit speed and the peripheral rotation speeds of the front and rear rows of rotary working bodies on the quality of soil crumbling and fuel consumption when performing early spring tillage was evaluated, based on which rational values of the indicated parameters.

Table 4. Matrix of the symmetric quasi-D-optimal Pesochinsky design $(\mathrm{k}=3)$

\begin{tabular}{|c|c|c|c|}
\hline \multirow{2}{*}{$\begin{array}{c}\text { Experiment } \\
\text { number }\end{array}$} & \multicolumn{3}{|c|}{ Combinations of factor values } \\
\cline { 2 - 4 } & $X 1$ & $X 2$ & $X 3$ \\
\hline 1 & 0 & + & + \\
\hline 2 & 0 & - & + \\
\hline 3 & 0 & + & - \\
\hline 4 & 0 & - & - \\
\hline 5 & + & 0 & + \\
\hline 6 & - & 0 & + \\
\hline 7 & + & 0 & - \\
\hline 8 & - & 0 & - \\
\hline 9 & + & + & 0 \\
\hline 10 & - & + & 0 \\
\hline 11 & + & - & 0 \\
\hline 12 & - & - & 0 \\
\hline 13 & 0 & 0 & 0 \\
\hline
\end{tabular}

\section{Results}

As a result of a series of experiments on the symmetric non-compositional quasi-D-optimal plan of Pesochinsky, the following values of the specific energy consumption Ec $[\mathrm{g} /(\mathrm{h} \cdot \%)]$ were obtained (Table 5).

Table 5. Results of Pesochinsky symmetric quasi-D-optimal plan

\begin{tabular}{|c|c|c|c|c|}
\hline $\begin{array}{c}\text { № } \\
\text { experiment }\end{array}$ & K1 & $\mathbf{K 2}$ & $\begin{array}{c}\mathbf{V p} \\
\mathbf{K m} / \mathbf{h}\end{array}$ & $\begin{array}{c}\mathbf{E c} \\
\mathbf{g} /(\mathbf{h} \cdot \%)\end{array}$ \\
\hline 1 & 1.1 & 1.2 & 11 & 92.2933 \\
\hline 2 & 1.1 & 1.1 & 11 & 96.3800 \\
\hline 3 & 1.1 & 1.2 & 7.2 & 83.0500 \\
\hline 4 & 1.1 & 1.1 & 7.2 & 86.4867 \\
\hline 5 & 1.15 & 1.15 & 11 & 93.3100 \\
\hline 6 & 1.05 & 1.15 & 11 & 95.2433 \\
\hline 7 & 1.15 & 1.15 & 7.2 & 83.9967 \\
\hline 8 & 1.05 & 1.15 & 7.2 & 85.4500 \\
\hline 9 & 1.15 & 1.2 & 9.1 & 87.0100 \\
\hline 10 & 1.05 & 1.2 & 9.1 & 88.5400 \\
\hline 11 & 1.15 & 1.1 & 9.1 & 90.6033 \\
\hline 12 & 1.05 & 1.1 & 9.1 & 92.5100 \\
\hline 13 & 1.1 & 1.15 & 9.1 & 87.4000 \\
\hline
\end{tabular}

The following regression equation was obtained after carrying out the regression analysis of the results of the experiments:

$$
\begin{aligned}
& y=86.8+1.875 x_{1}+1.925 x_{2}+3.75 x_{3}-0.35 x_{1} x_{2}+ \\
& +2.025 x_{1}^{2}+1.825 x_{2}^{2}+1.675 x_{3}^{2}
\end{aligned}
$$

Replacing the coded values of the factors in the regression equation with natural ones according to the formulas: 


$$
x_{1}=\frac{\mathrm{K}_{1}-1,1}{0,05} ; x_{2}=\frac{\mathrm{K}_{2}-1,15}{0,05} ; x_{3}=\frac{V_{p}-9,1}{1,9},
$$

the following regression equation was obtained in natural decoded form:

$$
\begin{aligned}
& E c=1790,2-1583,5 K_{1}-1486,5 K_{2}-6,47 V_{P}+ \\
& +810 K_{1}^{2}+730 K_{2}^{2}+0,46 V_{P}^{2}-140 K_{1} K_{2}
\end{aligned}
$$

At the operating speed of the unit $\mathrm{Vp}=9.1 \mathrm{~km} / \mathrm{h}$, the regression equation will take the following form:

$$
\begin{aligned}
& E c=1769,7-1583,5 K_{1}-1486,5 K_{2}+ \\
& +810 K_{1}^{2}+730 K_{2}^{2}-140 K_{1} K_{2}
\end{aligned}
$$

According to the regression equation (6), a graphical dependence of the change in specific energy consumption (EU) is plotted depending on kinematic parameters of the 1st (K1) and 2nd (K2) rows of needle disks, in the form of a cross-section of the response surface (Figure 2).

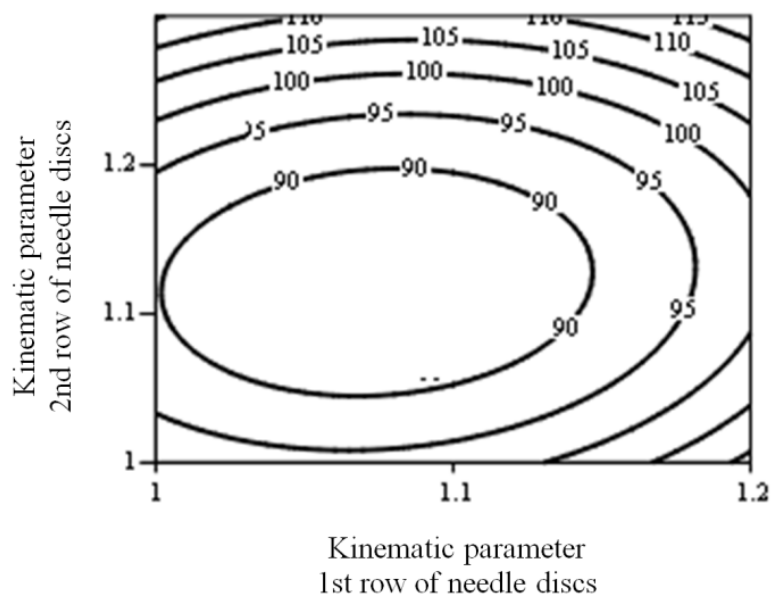

Fig. 3. Factor dependence of specific energy consumption

To determine the optimal values of the kinematic parameters of the 1 st $(\mathrm{K} 1)$ and 2 nd $(\mathrm{K} 2)$ rows of needle disks, we differentiate equation (2), determining the first-order derivatives with respect to each variable and equating them to zero:

$$
\left.\begin{array}{l}
\frac{\partial E c}{\partial K_{1}}=-1583,5+810 \cdot K_{1}-140 \cdot K_{2}=0 \\
\frac{\partial E c}{\partial K_{2}}=-1486,5+730 \cdot K_{2}-140 \cdot K_{1}=0
\end{array}\right\}
$$

Solving the resulting system of equations (7), the optimal values of the factors were found: kinematic parameter of the 1 st row of needle disks $\mathrm{K} 1=1.08$; kinematic parameter of the 2 nd row of needle disks $\mathrm{K} 2=$ 1.13 at the operating speed of the unit $\mathrm{Vp}=9.1 \mathrm{~km} / \mathrm{h}$. With the given values of the factors, the specific energy consumption of the EU does not exceed $90 \mathrm{~g} /(\mathrm{h} \bullet \%)$.

\section{Discussion}

As a result of a series of experiments following the Pesochinsky symmetric noncompositional quasi-D- optimal plan and regression analysis of the experimental results, a graphical dependence of the change in specific energy consumption (EY) was constructed depending on the kinematic parameters of the 1st (K1) and 2nd (K2) rows of needle discs, in the form of a cross-section of the response surface (Figure 2). A visual analysis of this graphical dependence clearly shows the ranges of the optimal values of the factors. The same ranges are confirmed by solving a system of first-order differential equations for each variable (7).

\section{Conclusions}

Highly energy efficient early-spring tillage can be achieved through the use of traction-driven tillage implements with active working bodies that do not create high tractive resistance and do not require a large traction-coupling weight of the aggregating tractor. A decrease in the traction resistance of such implements is achieved by transferring the main share of the power through the tractor PTO to the driven rotary working bodies, which create a pushing force, minimizing the tractive resistance of the tillage implement. The best energy efficiency of the traction-driven tillage implement is ensured by the optimal values of such factors as the kinematic parameter of the 1 st row of needle disks $\mathrm{K} 1=1.08$; kinematic parameter of the 2 nd row of needle disks $\mathrm{K} 2=1.13$, the optimal values of which are determined at the operating speed of the unit $\mathrm{Vp}=9.1 \mathrm{~km} / \mathrm{h}$. With the given values of the factors, the specific energy consumption of the EU does not exceed $90 \mathrm{~g} /(\mathrm{h} \cdot \%)$.

\section{References}

1. M.N. Chatkin, Kinematics and dynamics of rotary tillers working bodies with screw elements, Monograph (2008)

2. P.P. Nalavade, V.M. Salokhe, T. Niyamapa, P. Soni, Performance of free rolling and powered tillage discs, Soil and tillage research (2010)

3. P.P. Nalavade, V.M. Salokhe, T. Niyamapa, P. Soni, Development of a disc harrow for on-farm crop residue management, Int. Agric. Eng. J., 22, 49-60 (2013)

4. R.M. Musin, R.R. Mingalimov, Improved cultivator units with propulsion-rippers, Monograph (2012)

5. R.R. Mingalimov, R.M. Musin, Study of the formation and use of an additional driving force of machine-tractor unit as a result of the use of propulsion-rippers, Bull. of the Ulyanovsk SAA, 29, 126-132 (2015)

6. Pat. Russian Federation 2538810. An instrument for surface tillage (2015)

7. A. Petrov, Yu. Saveliev, P. Ishkin, M. Petrov, Soil tillage energy efficiency increase, BIO Web Conf., 17, 00177 (2020), DOI: https://doi.org/10.1051/bioconf/20201700177 
8. B.A. Dospekhov, Technique of field experiment (with the basics of statistical processing of research results), Monograph (1985)

9. GOST P 52777-2007, Tests agricultural machinery. Methods energy estimate (2008)
10. F.M. Zoz, R.D. Grisso, "Traction and Tractor Performance", ASAE Distinguished Lecture no. 27, Agricultural Equipment Technology Conf. (9-11 February 2003, Louisville, Kentucky, USA) (2003) 